\title{
Particle Swarm Optimization Application for Optimal Location of Multiple Distributed Generators in Power Distribution Network
}

\author{
Mounika Lakshmi Prasanna K ${ }^{1}$, Amit Jain ${ }^{1}$ and James Ranjith Kumar $\mathbf{R}^{2 *}$ \\ ${ }^{1}$ Central Power Research Institute, Bengaluru, Karnataka, India \\ ${ }^{2}$ National University of Singapore, Singapore
}

\begin{abstract}
Distributed generators (DGs) play a vital role in present power distribution networks. The integration of distributed generators in distribution systems require optimal placement and sizing of distributed generators to yield minimum power losses and improved voltage profile. Often single DG placement may not be sufficient for power distribution system and multiple DGs may be required to be integrated to power distribution network. Concerning this, optimal location of multiple DGs in power distribution systems is very important. This paper presents a Particle Swarm Optimization (PSO) based algorithm for optimal location of multiple DGs into the power distribution network for power loss minimization. The proposed algorithm has two major steps; first step is the finding of optimal location and active power injections of multiple DGs and later is the computation of optimal reactive power injection of DGs. A bio-inspired particle swarm optimization algorithm is used in the first step to locate multiple DGs optimally and to obtain optimal active power injections of DGs. In the second step, reactive power injections of DGs are selected based on the reactive power requirement of the area fed by the DG. The proposed method is successfully tested on IEEE 13 bus system and its performance has been benchmarked with the Improved Analytical method.
\end{abstract}

Keywords: Distributed Generation (DG); Particle Swarm Optimization (PSO); Power losses; Radial distribution network; Renewable energy sources; Voltage profile

\section{Introduction}

Distributed generation can also be termed as decentralized generation, embedded generation and dispersed generation. Distributed generation is about generating electricity at small scale and located close to the consumers. Abundant in nature and pollution free operation of renewable energy resources has made renewable energy based DGs major desirable components of today's power distribution network. Among all renewable energy resources solar and wind based DGs are widely employed due to their most abundant nature.

Proper incorporation of DGs has several advantages like lower distribution cost, higher reliability etc. Major advantages of integration of DGs in power distribution networks are power loss reduction and voltage profile improvement $[1,2]$. However, improper incorporation of DGs may lead to jeopardize system operation [3,4]. Henceforth, to take more benefits, DGs should be incorporated optimally so that system operation can be further improved with the integration of multiple DGs. Several methods have been proposed in literature for DGs placement and preferable size planning.

Various traditional and non-traditional techniques have been developed by many researchers for siting and sizing of multiple DGs [5-7]. Naik et al. [8] have proposed an analytical algorithm for optimal allocation of single as well as multiple DGs for power loss minimization. An improved analytical method has been introduced by Hung and Mithulananthan [9] for multiple DG allocation to minimize active power losses. To show the effectiveness of the improved analytical method, Hung and Mithulananthan [9] compared LSF and ELF methods with the improved analytical method.

A bio-inspired particle swarm optimization is one of the popular techniques used for placement of multiple DGs considering various objective functions [10]. Particle swarm optimization follows bird flocking and obtains the solution by moving towards the optimal solution with randomly generated initial particles. Naveen et al. [11] developed a new PSO based multiple DG placement and sizing technique for a network having different types of loads. A two stage method has been proposed, which utilizes PSO in the former stage to get optimal size of DG and then by placing one DG at a time compares load sensitivity factors to obtain the best location. Then in the later stage sizing of DG is done using PSO, GA etc. Jamian et al. [12] developed meta-heuristic REPSO algorithm for optimal allocation of DG, which results into less line capacity increment along with network power loss minimization. A new hybrid algorithm for optimal allocation of single DG to achieve power loss reduction and voltage profile improvement is proposed [13].

In this paper, a new technique is developed for optimal location and sizing of multiple DGs. The proposed method is a two stage technique; the first stage involves selection of siting of DGs and computation of active power injection of DGs using particle swarm optimization technique. In the second stage optimal reactive power injection is computed by using reactive loads of buses and reactive losses of the branches fed by the DG, which is briefly explained in the later sections. For validation of the proposed technique, it is implemented on IEEE 13 bus test system and results are discussed in the following sections.

\section{Methodology}

The proposed method for optimal location of multiple DGs considers active power loss of an entire system. The active power loss of an entire system is determined by exact power loss formula [14,15].

*Corresponding author: James Ranjith Kumar R, National University of Singapore, Singapore, Tel: +65 6516 6666; E-mail: amitjain@cpri.in

Received October 25, 2017; Accepted December 05, 2017; Published December 12, 2017

Citation: Mounika Lakshmi Prasanna K, Jain A, James Ranjith Kumar R (2017) Particle Swarm Optimization Application for Optimal Location of Multiple Distributed Generators in Power Distribution Network. J Electr Electron Syst 6: 244. doi: 10.4172/2332-0796.1000244

Copyright: (c) 2017 Mounika Lakshmi Prasanna K, et al. This is an open-access article distributed under the terms of the Creative Commons Attribution License, which permits unrestricted use, distribution, and reproduction in any medium, provided the original author and source are credited. 
Citation: Mounika Lakshmi Prasanna K, Jain A, James Ranjith Kumar R (2017) Particle Swarm Optimization Application for Optimal Location of Multiple Distributed Generators in Power Distribution Network. J Electr Electron Syst 6: 244. doi: 10.4172/2332-0796.1000244

Page 2 of 4

$$
P_{L}=\sum_{m=1}^{N b} \sum_{n=1}^{N b}\left[\alpha_{m n}\left(P_{m} P_{n}+Q_{m} Q_{n}\right)+\beta_{m n}\left(Q_{m} P_{n}+P_{m} Q_{n}\right)\right]
$$

Where,

$$
\begin{aligned}
& \alpha_{m n}=\frac{r_{m n}}{V_{m} V_{n}} \cos \left(\delta_{m}-\delta_{n}\right) \\
& \beta_{m n}=\frac{r_{m n}}{V_{m} V_{n}} \sin \left(\delta_{m}-\delta_{n}\right) \\
& V_{m}<\delta_{m} \text { is the complex voltage at the } m^{\text {th }} \text { bus; }
\end{aligned}
$$

$r_{m n}$ is the real part of $m n^{\text {th }}$ element of [ $Z$ bus] impedance matrix;

$P_{m}$ and $P_{n}$ are active power injections at the $m^{\text {th }}$ and $n^{\text {th }}$ buses respectively;

$m Q$ and $n Q$ are reactive power injections at the $m^{\text {th }}$ and $n^{\text {th }}$ buses respectively;

$\mathrm{Nb}$ is the number of buses.

The proposed optimal DG allocation algorithm has been done in two stages. In the first stage, PSO technique is used for allocating DG in optimal location and to obtain active power injection of DG. Then in the later stage optimal reactive power injection of DG is computed by adding the sum of reactive loads of the buses and reactive power losses of the branches that are fed by the DG. The same process is repeated till the optimal allocation of all DGs over.

\section{Optimal location and active power injection of DG}

In the present paper, optimal location and active power injection of DGs are obtained using PSO technique. PSO is a nature-inspired algorithm that randomly generates an initial population and the generated particles move towards the optimal solution [15]. Here, active power injection and location of DG are considered as particles. By properly tuning all other parameters, optimal location and active power injection of DG are obtained by continuously updating velocity and position using eqns. (2) and (3) till optimal solution is reached.

$$
\begin{aligned}
& V_{i d}^{n+1}=V_{i d}^{n}+c_{1} r_{1}\left(p b_{i d}^{n}-x_{i d}^{n}\right)+c_{2} r_{2}\left(g b_{i d}^{n}-x_{i d}^{n}\right) \\
& x_{i d}^{n+1}=x_{i d}^{n}+V_{i d}^{n+1}
\end{aligned}
$$

Where, $\mathrm{x}_{\mathrm{id}}$ and $\mathrm{v}_{\mathrm{id}}$ are the position and velocity of the particle; $i=1,2, \ldots, m ; m$ is the set of particles in solution space described as population $=\left[X_{1}, X_{2}, X_{3}, \ldots, X_{m}\right]$; the inertia weight is $w ; c_{1}$ and $c_{2}$ are the acceleration constants; and $r_{1} \& r_{2}$ are any two random values in the range $[0,1]$.

\section{Reactive power injection of DG}

In this paper a new method for computation of reactive power injection of DGs is proposed. Install DG with optimal active power injection at an optimal location obtained in the first step. Then, observe the power flows in the network. With the installation of DG, negative power flows come into picture. Get the area, which is fed by DG and compute reactive power injection of DG to meet the reactive power demand of the area fed by the DG.

Consider a 5-bus system, shown in Figure 1. Where, initially type-1 DG is installed at bus 3. The installed DG is feeding the buses $2,3,4 \& 5$.

Then the reactive power injection of DG, $Q_{D G}$ is,

$$
Q_{D G}=\left(Q_{2}+Q_{3}+Q_{4}+Q_{5}\right)+\left(Q_{23 l o s s}+Q_{34 \text { loss }}+Q_{45 \text { loss }}\right)
$$

Where,

$Q_{m}$ is the reactive load of the $m^{\text {th }}$ bus

$Q_{m n l o s s}$ is the reactive power loss of the branch $m-n$

The flowchart for the multi-DG placement and preferable size computation is given in Figure 2.

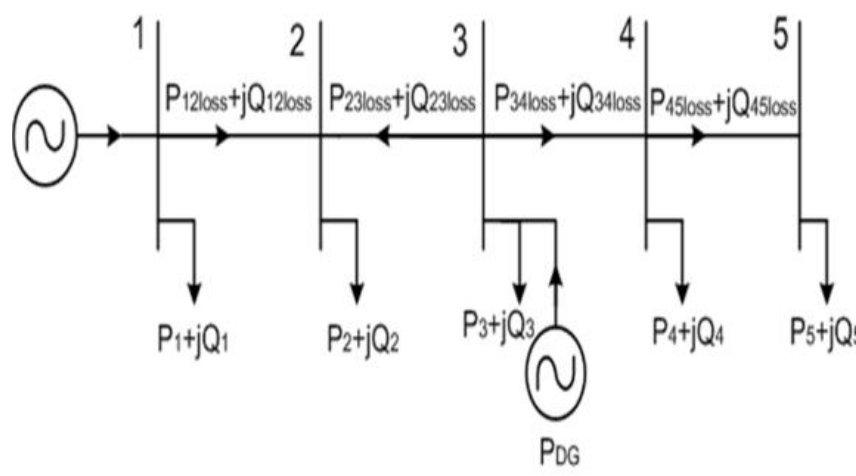

Figure 1: Sample 5 bus System.

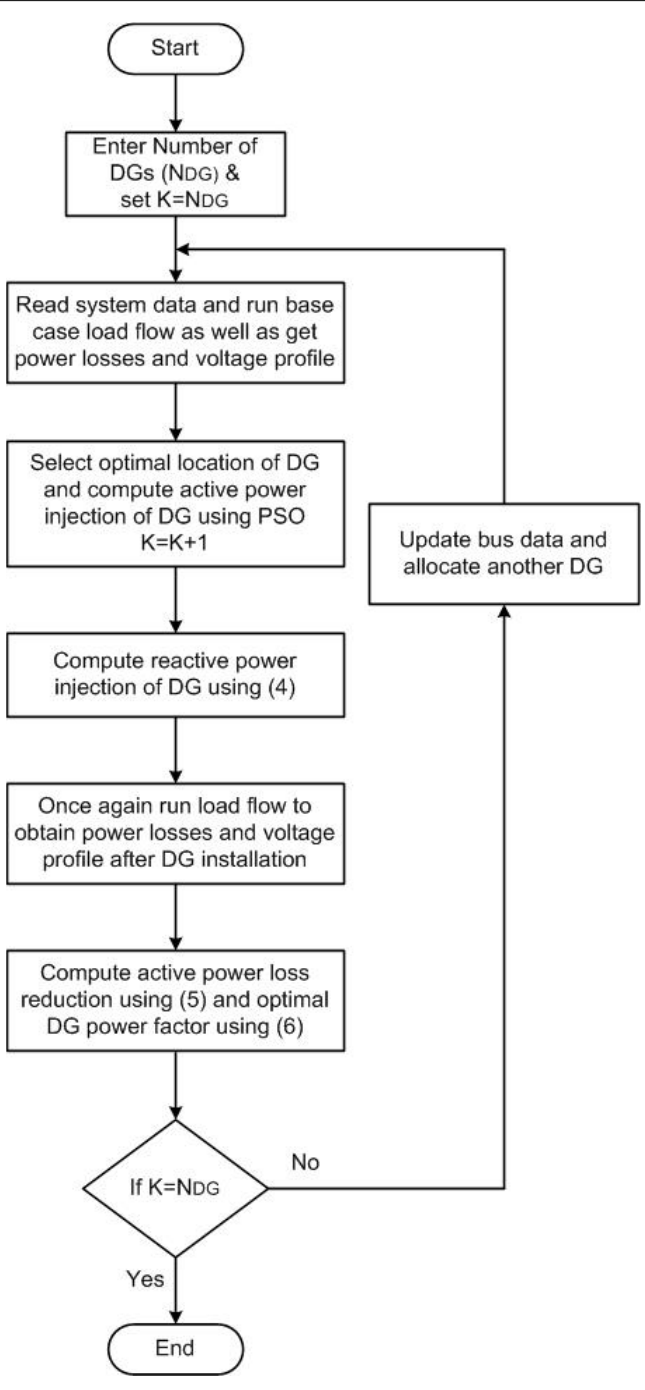

Figure 2: Flowchart of the proposed method. 
Citation: Mounika Lakshmi Prasanna K, Jain A, James Ranjith Kumar R (2017) Particle Swarm Optimization Application for Optimal Location of Multiple Distributed Generators in Power Distribution Network. J Electr Electron Syst 6: 244. doi: 10.4172/2332-0796.1000244

Page 3 of 4

\begin{tabular}{|c|c|c|c|c|c|c|c|c|}
\hline \multirow{4}{*}{ No DG } & \multirow[t]{4}{*}{ Method } & \multicolumn{3}{|l|}{ Installed DG } & \multirow{2}{*}{$\begin{array}{l}\text { Active power loss } \\
\text { (KW) }\end{array}$} & \multirow{2}{*}{$\begin{array}{l}\text { Minimum voltage } \\
\text { (PU) }\end{array}$} & \multirow{2}{*}{$\begin{array}{l}\text { Maximum voltage } \\
\text { (PU) }\end{array}$} & \multirow{2}{*}{$\begin{array}{l}\text { Active power loss } \\
\text { reduction (\%) }\end{array}$} \\
\hline & & Bus & & & & & & \\
\hline & & Power factor & & & 470.97 & 0.9456 & 1 & \\
\hline & & Size (KVA) & & & & & & \\
\hline \multirow[t]{6}{*}{ Single DG } & \multirow[t]{3}{*}{ IA [9] } & Bus & 7 & & & & & \\
\hline & & Power factor & 0.8693 lagging & & 17.93 & 0.9965 & 1.0001 & 96.19 \\
\hline & & Size (KVA) & 103.8947 & & & & & \\
\hline & \multirow{3}{*}{\begin{tabular}{|l|} 
Proposed \\
Technique
\end{tabular}} & Bus & 7 & & & & & \\
\hline & & Power factor & 0.8704 lagging & & 17.92 & 0.9966 & 1.0002 & 96.2 \\
\hline & & Size (KVA) & 103.8367 & & & & & \\
\hline \multirow[t]{6}{*}{ Two DGs } & \multirow[t]{3}{*}{ IA [9] } & Bus & 7 & 3 & & & & \\
\hline & & Power factor & 0.8693 lagging & 0.8693 lagging & 14.36 & 0.9979 & 1.002 & 97.36 \\
\hline & & Size (KVA) & 103.8947 & 12.2523 & & & & \\
\hline & \multirow{3}{*}{$\begin{array}{l}\text { Proposed } \\
\text { Technique }\end{array}$} & Bus & 7 & 3 & & & & \\
\hline & & Power factor & 0.8704 lagging & 0.8712 lagging & 14.33 & 0.9989 & 1.0027 & 97.38 \\
\hline & & Size (KVA) & 7 & 3 & & & & \\
\hline
\end{tabular}

Table 1: Comparison of the proposed method and other method by Hung, et al. [9] with respect to power losses for 13-bus system.

The active power loss reduction can be computed from base case active power loss $\left(P_{\text {Lbase }}\right)$ and active power loss of system after DG installation $\left(P_{\text {LwithDG }}\right)$ using,

$$
\% \text { power loss reduction }=\frac{\left(\mathrm{P}_{\mathrm{L}_{\text {base }}}-\mathrm{P}_{\mathrm{L}_{\text {withDG }}}\right)}{\mathrm{P}_{\mathrm{L}_{\text {base }}}} \times 100
$$

The optimal power of the installed DGs is computed using,

$$
P F_{D G}=\cos \left(\tan ^{-1}\left(\frac{Q_{D G}}{P_{D G}}\right)\right)
$$

\section{Simulation Results and Discussion}

The proposed method for optimal location of multiple DGs in power distribution network is implemented on IEEE 13 bus system. Matlab software is used for coding the proposed technique. IEEE 13bus power distribution system On IEEE 13-bus system two DGs are installed at buses 3 and 7, using the proposed technique. The power ratings of DGs placed at buses $7 \& 3$ are $103.8367 \mathrm{KVA}$ and 12.3476 KVA respectively as well as optimal power factors of the respective DGs are 0.8704 lagging and 0.8712 lagging. The active power loss is reduced from $470.97 \mathrm{KW}$ to $17.92 \mathrm{KW}$ and minimum voltage level is improved from 0.9456 to 0.9966 , after installation of first DG. With the installation of second DG, the active power loss is further reduced to $14.33 \mathrm{KW}$ and minimum voltage is improved to 0.9991 . The active power loss reduction and minimum and maximum voltage comparison with the other method [9] is shown in Table 1 and voltage profiles of the system before and after optimally locating multiple DGs are shown in Figure 3. The proposed method minimized the active power loss of and improved the voltage profile of both the test systems. From the obtained results it is concluded that the proposed method is competitive and somewhat better in performance when compared to other method [9].

\section{Conclusion}

The proposed technique effectively solved multiple DGs optimal location problem. Optimal locations and preferable active power injection of DGs are computed using PSO technique. The reactive power injection of DG is obtained by adding the reactive loads of buses and reactive losses of all lines in the area fed by the DGs. Through the optimal location of multiple DGs in the power distribution network, network power losses are minimized and voltage profile is improved.

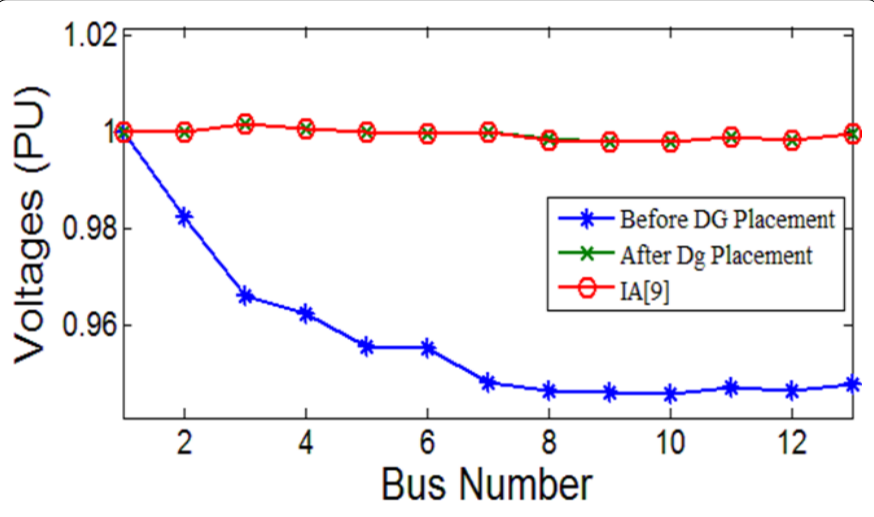

Figure 3: Voltage profile of 13 bus system before and after DGs placement.

To show the quality of solution, the proposed method is compared with the other method [9]. The proposed technique is competitive and somewhat better in performance than the other method [9].

\section{Acknowledgment}

The authors would like to acknowledge the support provided by the Central Power Research Institute, Bengaluru, India.

\section{References}

1. Hung DQ, Mithulananthan N, Bansal RC (2013) Analytical strategies for renewable distributed generation integration considering energy loss minimization. Applied Energy 105: 75-85.

2. Borges CLT, Falcão DM (2006) Optimal distributed generation allocation for reliability, losses, and voltage improvement. International Journal of Electrical Power \& Energy Systems 28: 413-420.

3. Acharya N, Mahat P, Mithulananthan N (2006) An analytical approach for DG allocation in primary distribution network. Int J Elect Power Energy Syst 28 : 669-678.

4. Atwa YM, El-Saadany EF, Salama MMA, Seethapathy R (2010) Optima renewable resources mix for distribution system energy loss minimization. IEEE Trans Power Syst 25: 360-370.

5. AlRashidi MR, AlHajri MF (2011) Optimal Planning of Multiple Distributed Generation Sources in Distribution Net-works: A New Approach. Energy Conversion and Management 52: 3301-3308.

6. Prommee W, Ongsakul W (2011) Optimal multiple distributed generation placement in microgrid system by improved reinitialized social structures particle swarm optimization. European Transactions on Electrical Power 21 489-504. 
Citation: Mounika Lakshmi Prasanna K, Jain A, James Ranjith Kumar R (2017) Particle Swarm Optimization Application for Optimal Location of Multiple Distributed Generators in Power Distribution Network. J Electr Electron Syst 6: 244. doi: 10.4172/2332-0796.1000244

7. El-Zonkoly AM (2011) Optimal placement of multi-distributed generation units including different load models using particle swarm optimisation. IET Gener Transm Distrib 5: 760-771.

8. Naik SNG, Khatod DK, Sharma MP (2015) Analytical approach for optimal siting and sizing of distributed generation in radial distribution networks. IET Generation, Transmission \& Distribution 9: 209-220.

9. Hung DQ, Mithulananthan N (2013) Multiple Distributed Generator Placement in Primary Distribution Networks for Loss Reduction. IEEE Transactions on Industrial Electronics 60: 1700-1708.

10. Rajalakshmi J, Durairaj S (2016) Review on optimal distributed generation placement using particle swarm optimization algorithms. 2016 International Conference on Emerging Trends in Engineering, Technology and Science (ICETETS), Pudukkottai, pp: 1-6.
11. Naveen J, Singh SN, Srivastava SC (2010) Particle swarm optimization based method for optimal siting and sizing of multiple distributed generators. 16th National Power Systems Conference, pp: 669-674.

12. Jamian JJ, Mustafa MW, Mukhtaruddin RNSR (2013) Optimal multiple distributed generation output and placement based on line capacity increment index. IEEE Student Conference on Research and Development, Putrajaya pp: 232-237.

13. Prasanna KML, Jain A, Ranjith JKR (2017) Optimal placement of distributed generation using hybrid technique. IEEE PES APPEEC.

14. Dhillon DPKAJS (2006) Power System Optimization. New Delhi: Prentice-Hall.

15. Kennedy J (2010) Particle Swarm Optimization, Encyclopedia of Machine Learning. Springer, US, pp. 760-766. 